\title{
Multinodular scleritis in a patient with rheumatoid arthritis
}

\author{
Meriem Ouederni ${ }^{1,2}$ (D) Hela Sassi ${ }^{1,2} \cdot$ Monia Cheour ${ }^{1,2}$ \\ Received: 20 February 2021 / Revised: 8 April 2021 / Accepted: 11 April 2021 / Published online: 16 April 2021 \\ (C) International League of Associations for Rheumatology (ILAR) 2021
}

\section{Presentation}

A 62-year-old woman with a history of rheumatoid arthritis (RA) receiving methotrexate for 17 years presented with progressing ocular pain for 4 weeks. She stopped treatment 2 months earlier due to nausea and vomiting and did not consult her internist. Visual acuity was $8 / 10$ in the right eye and $6 / 10$ in the left eye. Slit-lamp examination showed bilateral conjunctival injection with multiple scleral nodules predominating in the left eye (Fig. 1a). There were no signs of intraocular inflammation, and fundus examination findings were unremarkable in both eyes.

A diagnosis of anterior nodular scleritis with multiple nodules complicating active RA was made. The patient received topical steroids and was put on oral leflunomide by her internal physician with a 6-week course of oral methylprednisolone $16 \mathrm{mg}$ per day followed by gradual tapering.

At the 3-month follow-up, we observed complete regression of nodular scleritis in the right eye as well as the appearance of scleromalacia perforans with choroid bulging and peripheral ulcerative keratitis (Fig. 1b).

\section{Discussion}

Scleritis is a rare extra articular manifestation of RA $(0.2$ to $6.3 \%$ ) [1]. It tends to occur in patients with severe disease [2].

The two main types of anterior scleritis are necrotizing and nonnecrotizing scleritis, which can be diffuse or nodular [2]. Nodular scleritis has been reported in $20 \%$ of cases. It typically manifests as a single nodule and less frequently as multiple nodules, such as in our case [3, 4]. Although described in literature, multinodular scleritis in patients with RA had not been illustrated before to the best of our knowledge. Our patient had this unusual presentation in relation to her systemic condition.

Immunosuppressive agents are the first-line treatment for scleritis in patients with RA [2]. Adalimumab has been previously reported to be effective in patients who are unable to

Meriem Ouederni

meriem.oued@hotmail.com

Hela Sassi

helaa.sassi@gmail.com

Monia Cheour

moniacheour@yahoo.fr

1 Department of Ophthalmology, Habib Thameur Hospital, Tunis, Tunisia

2 University of Tunis El Manar, Tunis, Tunisia 
Fig. 1 Anterior segment photography of the left eye. a Anterior scleritis with multiple nodules (at presentation). b "Scleromalacia perforans" with choroid bulging associated with peripheral ulcerative keratitis (at follow-up)

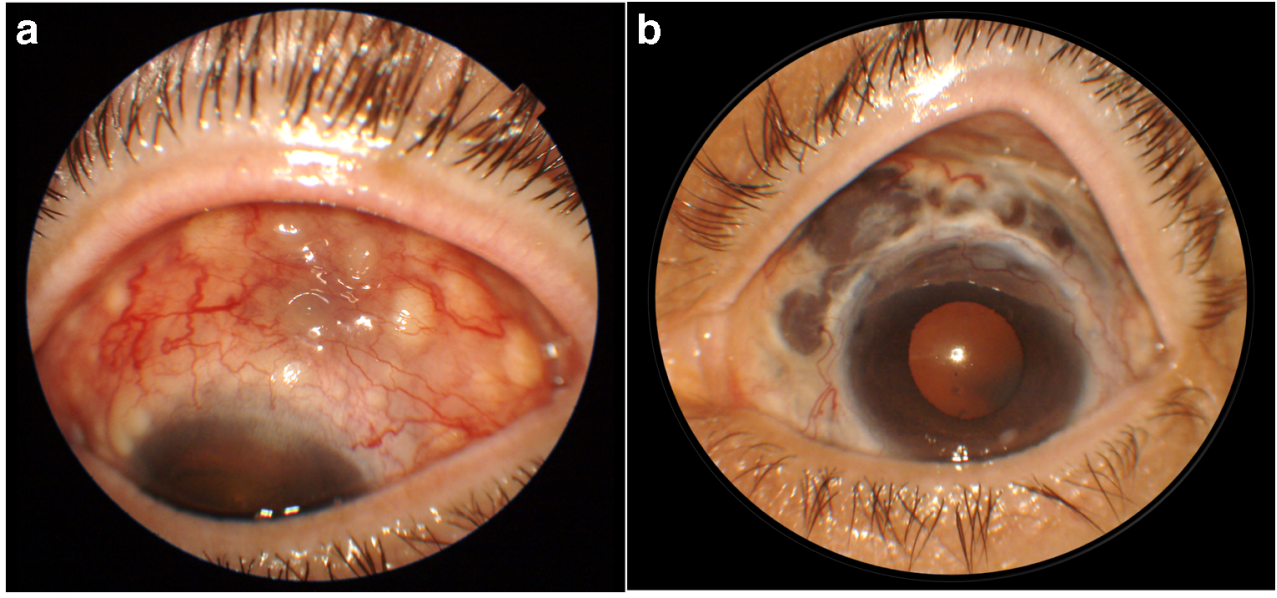

receive conventional treatment [3]. In our patient who was intolerant to methotrexate, leflunomide was a good therapeutic option, resulting in the resolution of nodular scleritis but with residual scleral thinning.

\section{Declarations}

Ethics approval Written patient consent for publication was obtained.

\section{Consent to participate Not applicable.}

Consent for publication Not applicable.

Disclosures None.

\section{References}

1. Artifoni M, Rothschild PR, Brézin A, Guillevin L, Puéchal X (2014) Ocular inflammatory diseases associated with rheumatoid arthritis. Nat Rev Rheumatol 10(2):108-116

2. Bhamra MS, Gondal I, Amarnani A et al (2019) Ocular manifestations of rheumatoid arthritis: implications of recent clinical trials. Int J Clin Res Trials 4(2):139

3. Restrepo JP, Molina MP (2010) Successful treatment of severe nodular scleritis with adalimumab. Clin Rheumatol 29(5):559-561

4. Patnaik G, Sudharshan S, George AE, Ganesh SK, Biswas J, Dutta Majumder P (2020) Clinical profile of patients with anterior nodular scleritis in India. Indian J Ophthalmol 68(9):1925-1928

Publisher's note Springer Nature remains neutral with regard to jurisdictional claims in published maps and institutional affiliations. 